\title{
Uso da história em quadrinhos na educação ambiental em Santo Antônio de Pádua, RJ
}

\author{
The use of comics in environmental education in Santo Antônio de Pádua, RJ
}

Sebastião Duarte Dias, Claudia de Vilhena Schayer Sabino, Wolney Lobato

Programa de Pós-Graduação em Ensino de Clências Matemática, Pontifícia Universidade Católica de Minas Gerais (PuC Minas), Belo Horizonte - Minas Gerais

E-MAL: SEBASTIAODUARTEDIAS@YAHOO.COM.BR, SABINOC@PUCMINAS.BR, PESQUISAPROPPG@PUCMINAS.BR

Abstract: Comics, if appropriated by the school world, can become a didactic material because they facilitate the learning of the different disciplines, since they represent a type of reading that appeals to children and youth. The objective of this work was to create, apply and evaluate a comic magazine, with high school students, that portrays the environmental impacts caused by the extraction of ornamental rocks in the municipality of Santo Antônio de Pádua, RJ. For the development of the work involved, students and teachers worked as a team in the production of the script, dialogues, scenarios and illustrations. Other students at the school have studied the magazine and other teachers evaluated it. The results showed that comics can be used as a learning object that associates contents, images and symbols, contributing to teamwork. It stimulates attention, interest and satisfaction in participating and intellectual autonomy.

\author{
Manuscrito: \\ Recebido: 04/04/2019 \\ Corrigido: $28 / \mathrm{jul} / 2019$ \\ Aceito: $30 / 08 / 2019$
}

Citação: Dias, S. D.; Sabino,C. V. S.; \& Lobato, W. (2019). Uso da história em quadrinhos na educação ambiental em Santo Antônio de Pádua, RJ. Terræ Didatica, 15, 1-12, e19032. doi: 10.20396/td.v15i0.8655109

Palavras-chave: Trabalho em equipe, Metodologia de ensino, Ensino médio.

\section{Introdução}

As histórias em quadrinhos (HQs) estão presentes desde o século XIX e o precursor dessa arte de comunicação foi o americano Richard Outcault, pioneiro ao utilizar o recurso das falas em seus desenhos por meio do esboço de balões e sinais gráficos (Rauber \& Medina, 2013).

Ao lado de jornais e revistas e agora a internet, as HQs representam uma das mais difundidas formas de comunicação de massa, alcançando, por meio de suas características universalmente conhecidas, uma influência considerável na formação de seu público (Testoni \& Abib, 2003). Deve-se notar ainda que foi nos jornais que as HQs surgiram como entretenimento barato. Ganharam destaque mundialmente com o lançamento dos super-heróis, cada vez mais populares entre os leitores jovens (Rauber \& Medina, 2013).

No Brasil, a data de surgimento dos quadrinhos foi o dia 30 de janeiro de 1869 , primeira publicação do personagem Nhô Quim, de Ângelo Agostini, na revista Vida Fluminense. Nessa data é comemorado o dia do quadrinho brasileiro (Santo et al., 2012, Assis \& Marinho, 2016).
Já no início do século XX (1905), revistas para crianças, como Tico-Tico do desenhista Renato de Castro, inspirada na revista infantil francesa ' $\mathrm{La}$ Semaine de Suzett' e Sesinho, lançaram quadrinhos de grande sucesso (Rauber \& Medina, 2013).

É importante notar que no Brasil, o ano de 1996 é um marco importante para a trajetória de aceitação das histórias em quadrinhos como ferramenta pedagógica. Nesse ano ocorreu a promulgação da Lei de Diretrizes e Bases da Educação Nacional (LDB) (Brasil, 2006) que, de certa forma, propôs um pacto entre este produto cultural midiático e a educação formal. Nesse sentido, ela

\footnotetext{
"[...] apontava para a necessidade de inserção de outras linguagens e manifestações artísticas nos ensinos fundamental e básico". (Vergueiro \& Ramos, 2009, p. 10).
}

A LDB relaciona a educação ambiental (EA) como tema transversal e os PCNs (Parâmetros curriculares Nacionais) deixam claro que a mesma deve ser trabalhada de forma interdisciplinar e em consonância com o contexto social. (Brasil, 1997), 
Porém, mesmo que a inserção desta temática seja atualmente uma realidade nos sistemas de ensino, sabe-se das dificuldades e desafios para exerce-la no dia-a-dia escolar (Brasil, 1999).

Diante desse cenário de dificuldade de compreensão dos conteúdos relacionados ao meio ambiente, os PCNs preconizaram o uso de materiais didáticos e recursos tecnológicos como estratégias de ensino para auxiliar na construção e reconstrução do conhecimento de forma significativa (Assis \& Marinho, 2016). Além disso, indicam a necessidade de se trabalhar competências relacionadas à interpretação do discurso das mídias em sala de aula, adotando inclusive HQs no Programa Nacional Biblioteca na Escola. (Programa Nacional Biblioteca na Escola, 2008). Os artigos $8^{\circ}$, incisos IV e V da Lei 9.795/99, incentivam a busca de alternativas curriculares e metodológicas na capacitação da área ambiental e as iniciativas e experiências locais e regionais, 'incluindo a produção de material educativo' (Parâmetros curriculares nacionais: Língua portuguesa, 1999).

Para Maffesoli (1995) a HQ é uma forma de expressão visual além da matéria, isto é, oriunda do imaginário e do sonho, descendentes do desenho narrativo. Eisner (1999), por sua vez, define as HQs como técnica sequencial, o arranjo de fotos ou imagens e palavras para narrar uma história ou dramatizar uma ideia.

Nesse sentido, as HQs representam uma forma de arte, em linguagem visual, que influencia os sentimentos humanos e transmite mensagens por meio de símbolos e imagens (Dalacosta, Kamariotaki, Palyvos \& Spyrellis, 2009), podem ser definidas como '[...] forma de expressão artística que tenta representar um movimento através do registro de imagens estáticas' (Guimarães, 1999, p. 1).

Tossin et al. (2017) salientam que a HQ é composta por: balões, cenários, onomatopeias, personagens, quadrinhos e planos. Assim, além dos balões, podem ser destacados: o uso de sinais gráficos como as onomatopeias (para a tradução dos sons) e as pequenas estrelas sobre a cabeça de um personagem (indicando dor ou tontura); o uso de linhas para separar um quadro de outro e estabelecer um sentido de evolução no tempo entre as cenas representadas; o uso de legendas para mostrar uma "voz do narrador" dentro da história; entre outros (Assis \& Marinho, 2016). Dessa forma, as HQs são mídias que combinam várias expressões artísticas com a comunicação, gerando um meio pelo qual o leitor pode se tornar parte da história, assim, criando sequências, sons e vozes por meio dos diálogos nos balões.

De acordo com Junqueira et al. (2007) é importante compreender os exemplos que denotam a possibilidade de trabalho com as HQs, sobretudo aqueles que tratam de alcance e educação da população em geral. Se apropriadas pelo mundo escolar, podem ser transformadas em material didático-pedagógico a ser incluído nas atividades de sala de aula, criando oportunidades de os alunos estabelecerem relações com os conteúdos das diferentes áreas ou disciplinas, pois é um tipo de leitura que agrada principalmente ao público infanto-juvenil. Segundo Giesta (2002), a importância das histórias em quadrinhos como veículo de comunicação é um dos motivos que atesta um grande valor à investigação sobre seus conteúdos impressos, principalmente quando explorado com sensibilidade e competência pelos professores nos diferentes níveis de escolarização, e até fora dos muros escolares;

HQs se constituem em um material dinâmico, que podem tratar a cada nova edição de temas diferentes, que requerem debate e que precisam chegar ao conhecimento de todos. São diferentes dos livros didáticos, que trazem geralmente o mesmo conteúdo estático por vários anos, sendo restritos os espaços dedicados a novas temáticas (Junqueira \& Pino, 2007). Possuem um poder de alcance muito amplo, visto que têm uma comunicação direta e de fácil compreensão, tendo grande potencial expressivo e linguagem visual. São mais especificamente voltadas ao público infanto-juvenil, sendo essa a etapa do desenvolvimento social e cognitivo, em que a pessoa assimila a maior parte dos conceitos que levará para o resto da vida;

Diferentemente de folders e cartilhas voltados à sensibilização da população para as problemáticas ambientais em momentos e eventos episódicos, as HQs podem tratar desses assuntos em momentos não específicos. (Junqueira \& Pino, 2007). Apesar de todos os argumentos até hoje as HQs não são efetivamente utilizadas nas escolas. (Ferreira, Godoy, Mendes \& Tocantins, 2016). Portanto, ao retratar uma época em que o tema meio ambiente se torna um desafio para a escola, esta obra se traduz em alternativa para auxiliar os professores, na tarefa de propor novas metodologias de ensino-aprendizagem, transformação e estruturação do conhecimento.

O objetivo deste trabalho foi criar, aplicar e avaliar, junto a alunos do ensino médio, uma pro- 
posta comunicativa para o ensino, por meio de uma revista de HQs, que retrata os impactos causados pela extração de rochas ornamentais no município Santo Antônio de Pádua, RJ.

\section{Etapas metodológicas}

\section{Caracterização da área de estudo}

O município de Santo Antônio de Pádua se localiza na região Noroeste Fluminense do estado do Rio de Janeiro e abrange uma extensão territorial de $603,357 \mathrm{~km}^{2}$, correspondentes a $11,2 \%$ da área total da região. A cidade fica a 86 metros acima do nível do mar, com latitude $21^{\circ} 32^{\prime} 22^{\prime}$, sul e longitude $42^{\circ} 10^{\prime} 49^{\prime}$, oeste. Situa-se a uma distância de $256 \mathrm{~km}$ da capital fluminense.

O desenvolvimento econômico de Santo Antônio de Pádua é semelhante ao de tantas outras cidades localizadas na região, alternando momentos de extrema riqueza, que apontam a região como referência econômica, social e cultural e momentos de extrema miséria ligados a uma estagnação econômica. Durante o correr dos anos o município passou por dois ciclos principais: o agropecuário, destacando-se: a cana de açúcar, o café, o arroz e a pecuária leiteira extensiva; e o minerário (Peiter, Carrisso, Pires, 2011).

As atividades minerárias, com relação à exploração de rochas ornamentais na região de Santo Antônio de Pádua, sinalizam que seu início foi na década de, 1960, quando alguns pequenos produtores rurais começaram a utilizar uma rocha facilmente desplacável e friável, para revestir o piso de currais. Esta era simplesmente retirada dos afloramentos, desplacada e assentada diretamente sobre os pisos (Peiter et al., 2011).

Atualmente, Santo Antônio de Pádua é o maior polo de extração mineral de rochas ornamentais do estado do Rio de janeiro. A atividade tem gerado cerca de 6 mil postos de trabalho direto e indiretos (Peiter et al., 2011). Atualmente existem mais de 200 pedreiras e mais de 100 serrarias em operação. Embora a explotação de rochas ornamentais em Santo Antônio de Pádua venha crescendo de maneira acentuada, as técnicas de extração são rudimentares, o que compromete a produtividade local e a competitividade nacional e internacional do segmento, sobretudo compromete bruscamente o meio ambiente da região (Peiter et al., 2011).

Todavia, a atividade mineradora é uma alterna- tiva de trabalho e consequentemente atrai a atenção das pessoas em busca de emprego e melhores condições de vida. As inquietações, em longo prazo se tornam um desafio, sobretudo social e ambiental, uma vez que se trata de um recurso não renovável, algo que cria um horizonte de incertezas em relação ao futuro da econômica local. Santo Antônio de Pádua possui a segunda maior população da região e concentra o segundo PIB do Noroeste Fluminense do estado do Rio de Janeiro, fica atrás apenas do município de Itaperuna (IBGE, 2019).

\section{Desenvolvimento da HQ}

Para o desenvolvimento do trabalho foram levados em consideração os PCNs e as diretrizes curriculares direcionadas ao Ensino Médio. Foram elencados os conteúdos pertinentes à questão socioambiental da região e enfatizados assuntos relacionados à extração de rochas ornamentais. A primeira atividade foi uma roda de conversa sobre a extração de pedras ornamentais na região e explicação sobre como seriam os trabalhos. Participaram da atividade 40 alunos e 4 professores (ciências, geografia, arte e matemática).

Em seguida, com as devidas autorizações, foi realizada uma visita técnica ao local de extração de pedras e às serrarias, para que os alunos se familiarizassem com a problemática e fotografassem (onde autorizado), para posterior utilização do material. Para elaborar uma HQ, o estudante precisa conhecer o tema que será abordado. Ele só deve criar suas tirinhas depois de aprender e refletir sobre um determinado conceito e não pode ser visto apenas como o desenhista que, mecanicamente, dará vida a uma ideia do professor. Sua criação deve ser fruto de um processo interativo, reflexivo e questionador (Caruso \& Silveira, 2009).

Foi solicitado então aos alunos que, em reunião em grupos, criassem o roteiro. Então as criações foram apresentadas e eleita a melhor. Contar histórias é uma ação inata no homem desde os primórdios da sua existência (Bugay, 2004). Simultaneamente ao roteiro, foram criados os personagens, que são os responsáveis por chamar o leitor a fazer parte da história ou somente querer conhecê-la. Talvez o passo mais importante para a criação de um personagem seja o de saber qual é a sua necessidade dramática. O que esse personagem faz na história? (Massarani, 2019). Um personagem bem construído é fundamental para o funcionamento do enredo e de sua narrativa. 
Não menos importante que o personagem foi o desenvolvimento do diálogo. Determinar o ritmo dos diálogos, escolher bem o vocabulário e dosar a quantidade de frases torna-se de suma importância na confecção de um roteiro bem-sucedido. Um diálogo é a interação entre personagens e seus papeis na história, sendo criado para alcançar o objetivo.

a construção das frases a serem ditas em cena merece tanta atenção quanto à elaboração dos elementos visuais. É preciso algo mais: o diálogo tem de fazer mais sentido, comunicar mais. Cada palavra conta. Afinal, a aproximação entre o personagem e o ser humano se dá pela fala que ele emite. Expressamos nossos pensamentos, emoções e angústias com as palavras, e isso também vale para a ficção. Bons diálogos fazem uma diferença muito grande em uma história (SENAC, 2014).

Após a criação básica dos diálogos, para que as ilustrações pudessem representar eficazmente a evolução da história por meio dos quadrinhos, foi necessária a roteirização de cada momento, nos quais foram detalhadas as falas, expressões dos personagens, bem como os cenários, nos quais as cenas aconteceriam.

As primeiras ilustrações foram desenvolvidas manualmente, utilizando lápis 4, 6 e $8 \mathrm{~B}$ sobre papel sulfite canson A4 e para a arte final foi usada caneta nanquim. Assim, os primeiros rascunhos do trabalho gráfico foram baseados no delineamento de traços simples, linhas necessárias para a elevação dos planos e projeção de um corpo em sintonia com uma cena. Posteriormente os desenhos foram digitalizados. Para colorir foi utilizado o Software design gráfico Coreldraw- X7, com a ajuda dos professores.

No que se refere à impressão da revista de HQs, foi feita uma tiragem de quarenta exemplares em formato A4 (21,0 x 29,7 cm), paginação colorida em papel Couché com brilho, $115 \mathrm{~g}$ (miolo), 170 $\mathrm{g}$ (capa) e acabamento com grampo. Vale ressaltar, que após a apresentação do trabalho e avaliação, os exemplares foram doados às bibliotecas do município, a fim de atender e propor ao público novas situações de lazer, leitura e aprendizagem. A impressão foi responsabilidade dos professores.

Para a apresentação da revista foi feita uma reunião com alunos que não participaram dos trabalhos, na qual foram feitas explicações do trabalho, leitura da revista em grupo e roda de conversa. Ao final foi solicitada entrega de comentários escritos.

A avaliação da revista, por meio de questionário, foi feita após leitura, por professores que integram o quadro de educadores dos colégios envolvidos.

\section{Resultados e discussão}

Roda de conversa: Durante a atividade, os alunos ficaram atentos e entusiasmados com o trabalho que seria realizado. A maioria nunca havia considerado a extração de rochas ornamentais um problema ambiental grave. Estavam mais conscientes das vantagens econômicas do que das desvantagens ambientais da atividade.

Visita técnica: Ao realizar a visita técnica eles perceberam a realidade associada à mineração. Entre os impactos ambientais causados foram salientados antes da visita: a construção de áreas de bota-fora, aberturas de estradas, maior exposição de solos, assoreamento de corpos de água, aumento da capacidade erosiva, supressão da vegetação, supressão de habitats, alteração da vegetação, alteração no ecossistema aquático, alteração estético-visual e alteração no uso do solo.

Ao chegar na serraria de rochas, alunos e professores foram recebidos pelo proprietário, que gentilmente autorizou o registro fotográfico e apresentou o espaço da empresa, bem como as condições e divisões de trabalho. Foi visitada a pedreira, uma rocha de formação geológica caracterizada por um gnaisse quartzo-feldspático, onde o grupo deu sequência à etapa de observação e coleta de dados.

As alterações naturais provocadas pelo processo de explotação de rochas são impressionantes. Os alunos ficaram por alguns momentos a observar. Essa foi uma etapa importante: o conhecimento da realidade ajuda o estudante a desenvolver suas capacidades criativas, pois se familiarizam com a situação e acabam se envolvendo diretamente com o assunto (Prado, Sousa Junior \& Pires, 2017).

O primeiro exercício, o do olhar, é a sensibilização para o local que se pretende trabalhar, seja por meio de fotos, de passeios, estudos do meio, caminhadas diagnósticas, buscando aguçar os sentidos para uma nova maneira de ver este local. Precisamos redescobrir os lugares, mesmo por onde passamos todos os dias, enxergar com novos olhos, perceber com outros sentidos (Públio Jr., 2018).

Uma das formas de problematizar determinado fenômeno em estudo é observar a realidade concreta. Nesse sentido, os alunos foram orientados a 
olhar atentamente e registrar de forma sistemática o que perceberam, para posterior uso na elaboração dos cenários da HQ que seria desenvolvida. Esse processo abre espaço para a metacognição, a busca por mais informações e tende a culminar numa aprendizagem mais significativa, pois o aluno estará realmente envolvido e interessado, sendo capaz de refletir, relacionar informações, ideias e recordações (Pereira \& Oliveira, 2016). Algumas fotos feitas pelos alunos estão apresentadas nas Figuras 1 e 2.

A criação do Roteiro: Após longas discussões, os alunos decidiram sobre o roteiro que seria desenvolvido e que resumidamente está apresentado na Figura 3.

O final feliz nas HQs deve ser lido como transcendência pessoal do homem. O mundo continua como está, mas graças à mudança de ênfase ou ponto de virada, um processo de transformação ocorre no interior do indivíduo. Para o herói das histórias em quadrinhos, o valor atribuído a essa missão é deveras importante, pois toda a trama girará em torno da aventura de descobertas e desafios. (Gomes, 2018)

Personagens: $\mathrm{O}$ roteiro da revista que estava sendo elaborada e posteriormente intitulada 'As aventuras de Capitão Petro e Granulito' foi baseado no forte senso de justiça estabelecido pelos Super Heróis (SH). Para Campos (2014), o SH é caracterizado principalmente por sua capacidade de se sacrificar pelo bem-estar comum. Tipo de fonte diferente em algumas palavras. A imagem e símbolos atribuídos aos super-heróis contribuem para encantar e distorcer a realidade que é formada por pessoas que sofrem, que se superam, que trabalham, que têm suas famílias e que envelhecem (Silva, Rossi Filho \& Origuela, 2016). Assim, quanto mais humano, próximo das qualidades das pessoas comuns, mais próximo dos leitores ele estará. Este protótipo será chamado para a aventura, sairá de seu mundo comum, passará por aventuras em que sua conduta e atitude serão postas à prova. Busca a restauração do mundo, e retornará transformado. Em relação às questões psicológicas, o herói é aquele capaz de transcender os limites e ilusões do ego. Este arquétipo representa a busca pela identificação do 'eu'. Campbell, 2007 afirma que as estruturas da narrativa do herói e seus feitos em histórias, lendas e fábulas, são arquetípicos de toda sociedade.

Foram propostas como características fundamentais dos personagens, a coragem e a atitude.

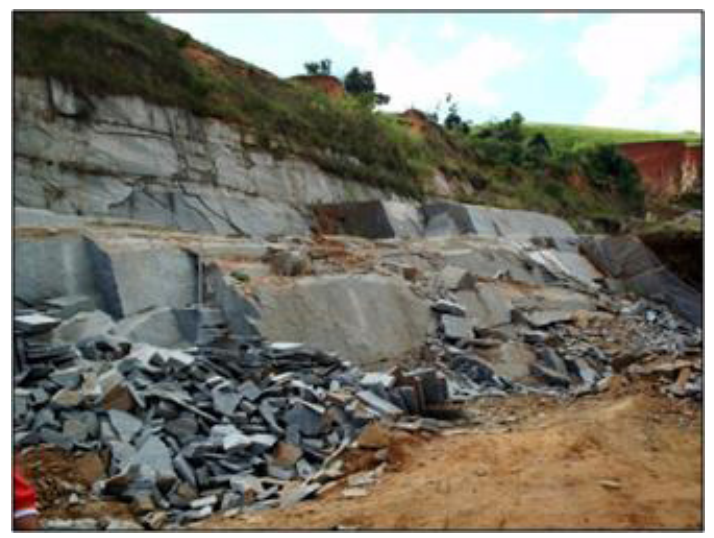

Figura 1. Rejeitos pétreos provenientes da extração mineraria, Serra do Bonfim, Pádua, RJ, Fonte: Alunos

Os protagonistas da história: dois jovens amigos: 'Capitão Petro e Granulito', decididos a mitigar os impactos causados pela extração de rochas ornamentais na cidade de 'Petrolita' lutam vertiginosamente, numa empreitada laboriosa para levar conhecimento e primorosas técnicas sustentáveis aos trabalhadores dessa prática de mineração.

Nesse sentido, diante da perspectiva aristotélica, 'Capitão Petro e Granulito' são seres virtuosos. Mas como eles se tornaram tais? Saber o que é virtude não basta, é necessário praticá-la porque os seres humanos se tornam bons e virtuosos, pela prática e repetição, assim como se adquire as artes e os ofícios: 'homens se tornam construtores, construindo casas e se tornam tocadores de lira tocando lira. Analogamente, nos tornamos justos realizando atos justos e corajosos realizando atos corajosos (Weschenfelder \& Kronbauer, 2010).

Diálogos: Nas HQs, as palavras e as ilustrações transmitem a ideia simultaneamente. Uma complementa a outra e juntas transmitem a mensagem. Os alunos compreenderam o fato ao elaborar os diálogos.

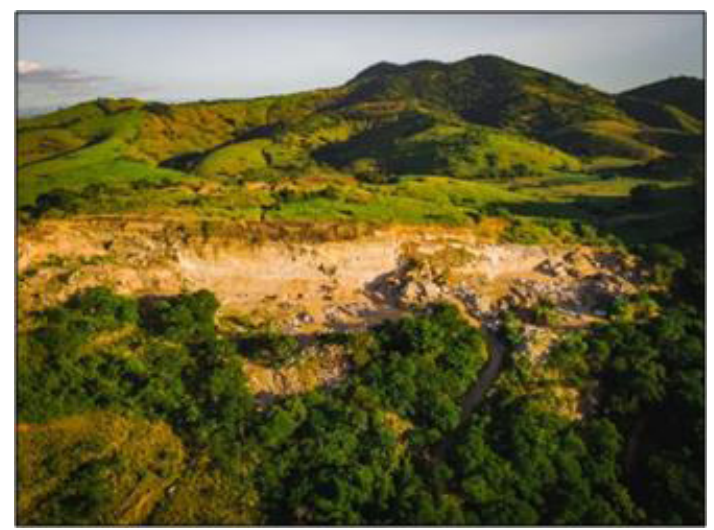

Figura 2. Degradação da paisagem na Serra do Catete, Pádua, RJ. Fonte: Alunos

\begin{tabular}{c|c|c|c|c|c|}
\hline (C) Terrae Didat. & Campinas, SP & v.15 & $1-12$ & $\mathrm{e} 019032$ & 2019 \\
\hline
\end{tabular}




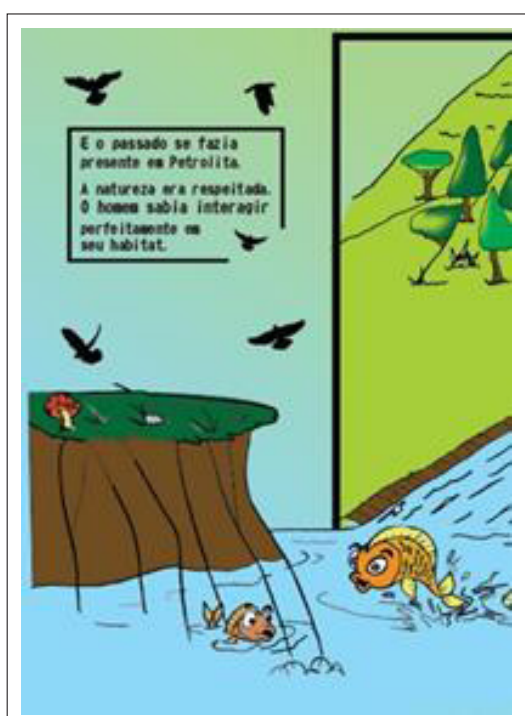

Era vez um lindo local, chamado Petrolita, onde o povo vivia feliz.

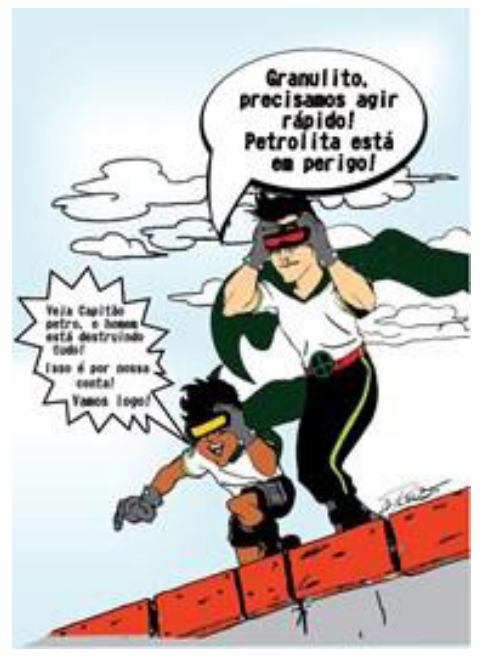

O Capitão Petro e Granulito, heróis regionais viram a situação e decidiram intervir.

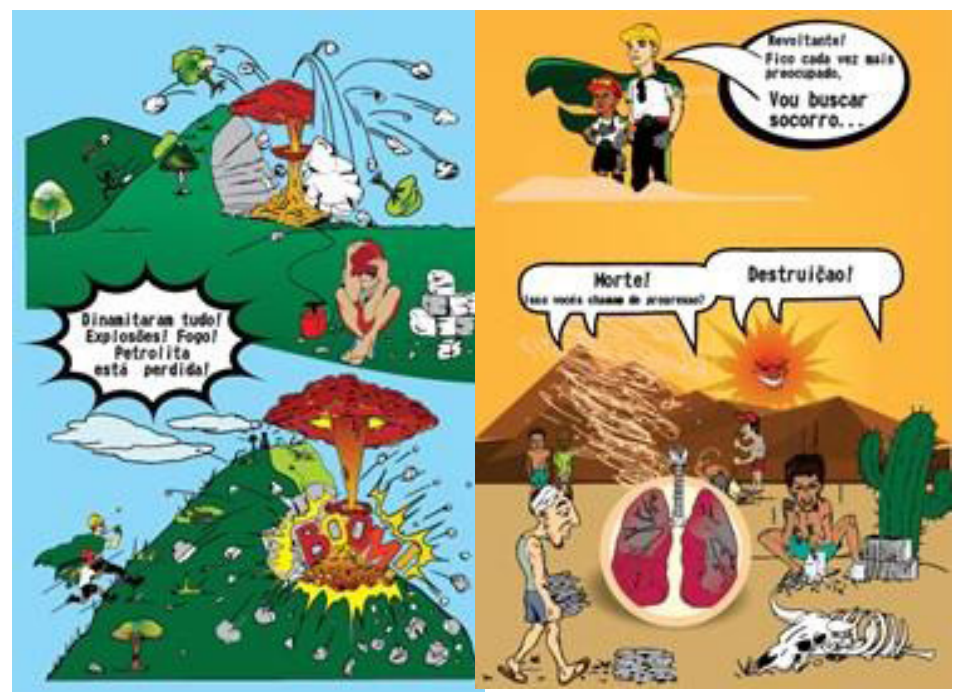

Veio a mineração e os funcioná- O solo se tornou árido e o rios dinamitaram e cavaram a povo ficou infeliz e faminto. terra destruindo o meio ambiente.

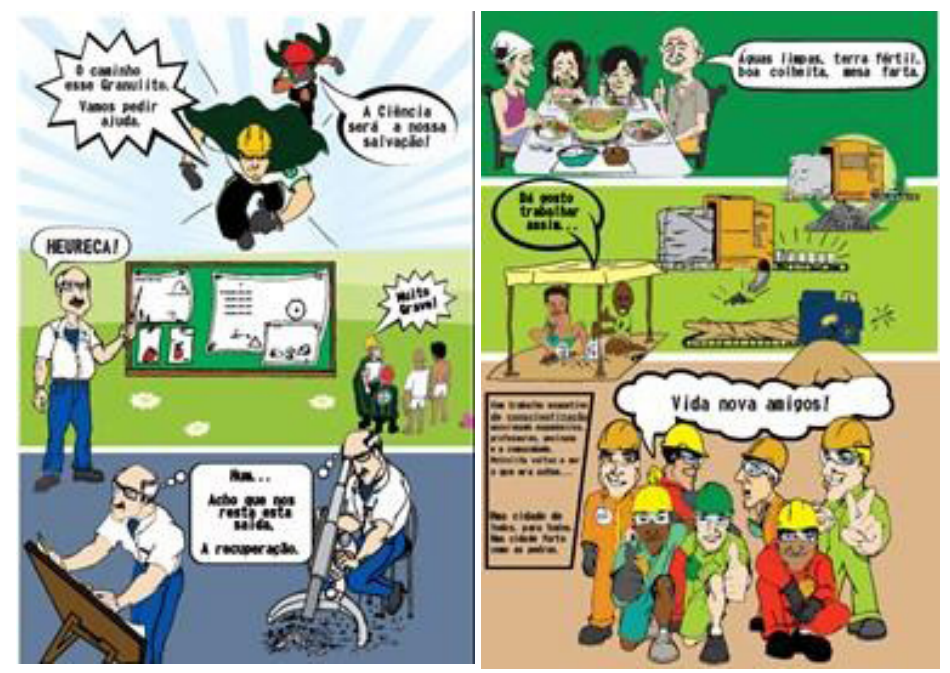

Buscaram apoio na ciência e As medidas foram eficientes na tecnologia para recuperar o e o povo voltou a ser feliz. ambiente e utilizarem técnicas de mineração sustentáveis

Figura 3. Resumo do roteiro elaborado e desenvolvido pelos alunos. Fonte: Os alunos

Para que as ilustrações pudessem representar eficazmente a evolução da história por meio dos quadrinhos, foi necessária a roteirização de cada diálogo, as falas foram detalhadas e reescritas para combinar com as expressões dos personagens e com o cenário.

No plano pedagógico, os quadrinhos proporcionam experiências narrativas desde o início do aprendizado, fazendo os alunos adquirirem uma nova linguagem. Crianças e adolescentes seguem a história do começo ao final, compreendem seu enredo, seus personagens, a noção de tempo e espaço, sem necessidade de palavras sofisticadas e habilidades de decodificação. As imagens apoiam o texto e dão aos alunos pistas contextuais para o significado da palavra. Os quadrinhos atuam como uma espécie de andaime para o conhecimento do estudante. (Luyten, 2011)

A partir dessa projeção, a história foi submetida à arte de ilustração interativamente. 
As histórias em quadrinhos fazem parte do nosso dia-a-dia. Esse interesse e o acesso que os alunos têm faz com que eles se sintam mais motivados e curiosos a desenvolver leituras e escritas em quadrinhos (Krüger \& Michels, 2018)

Um exemplo está apresentado na Figura 4.

Ilustração e diagramação: A princípio, as ilustrações foram desenvolvidas manualmente, com a participação e interação entre os alunos e professores. Cada grupo ficou encarregado de ilustrar uma parte da história e a diagramação e a arte final foram feitas por um professor. Nesta fase foi importante a interação entre professores e alunos, o que possibilitou um ensino nos moldes da pedagogia vislumbrada por Paulo Freire, que enfatiza uma forma de aprendizagem em que o relacionamento entre professor-aluno e aluno-aluno se dê por meio de uma troca de experiências e saberes, e não mais no modelo bancário pelo qual o professor, dito o dono da verdade, deposita no aluno conhecimentos não contextualizados (Prado, Sousa Junior \& Pires, 2017).

Os primeiros rascunhos do trabalho gráfico foram baseados no delineamento de traços simples, linhas necessárias para a elevação dos planos e projeção de um corpo em sintonia com uma cena. Um exemplo está apresentado na Figura 5.

Sempre que se trabalha com criação é importante não se esquecer dos rascunhos, que nada mais são do que um estudo preliminar para uma obra em geral. Eles são o pontapé inicial para que as ideias sejam apresentadas no papel, dando vida à criação. É comum ver desenhistas e pintores preparando seus desenhos com traços simples que, aos poucos, vão dando forma ao modelo final. Esse processo, além de facilitar na elaboração de ideias, poderá ser essencial para que o trabalho possa ser de fácil modificação e manuseio ou pela questão do desprendimento e flexibilidade que o autor obtém para suas adaptações (Moreto \& Nakata, 2018).

Após a conclusão dos esboços, foi feita a ilustração definitiva que foi digitalizada e colorida com ajuda dos professores (https://sabinoc.wixsite.com/ meusite-1).

Impressão: A revista foi impressa como prevista $\mathrm{e}$ teve o patrocínio da Universidade Iguaçu, Campus Itaperuna e Colégio Paiva, do município.

Apresentação do produto: A apresentação da revista foi realizada em reunião, por meio de uma leitura em grupos, de alunos do ensino médio (153 alunos divididos em grupos). A atividade oportunizou

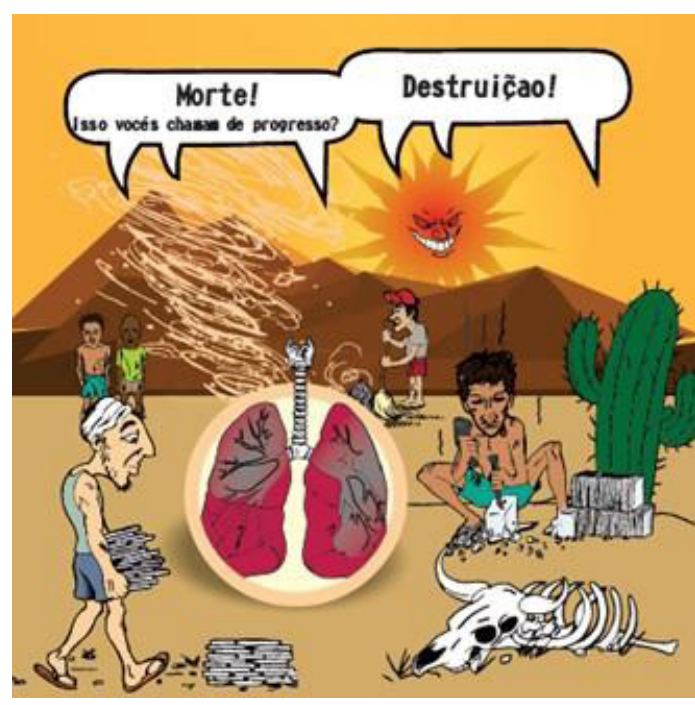

Figura 4. Complementação palavras e cenário na HQ. Fonte: Os alunos

momentos de reflexão, de forma participativa e interdisciplinar. Segundo Albuquerque (2010), o ato de ler articula o imaginário, se inter-relaciona com diferentes aspectos ao mesmo tempo, sem enfatizar mais um ou outro. Portanto, entre conversas e combinados, os próprios alunos interpretaram a fala de cada personagem da trama fazendo o uso de estratégias como a entonação de voz e ritmo, tudo isso de forma bem descontraída, a fim de prender a atenção dos colegas e, em equipe, vivenciar o contexto da HQs.

Nesse sentido, foi dado o devido valor à atividade de leitura como forma de lazer ativo, de crescimento pessoal, aliado à construção e à apropriação cultural, as quais inclusive agregam aptidões básicas de maior significado na formação do sujeito que zela pelo uso da linguagem escrita.

Ao contrário da escrita, que é uma atividade de exteriorizar o pensamento, a leitura é uma atividade

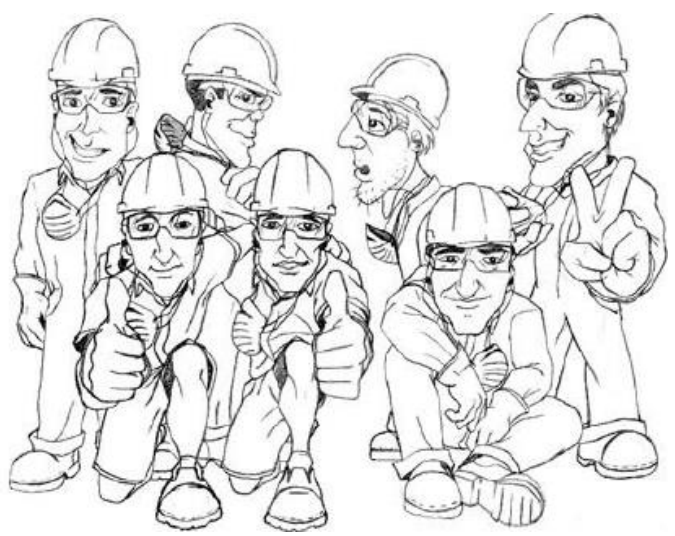

Figura 5. Exemplo do rascunho de quadrinho. Fonte: Os alunos 
de assimilação de conhecimento, de interiorização, de reflexão. De acordo com os Parâmetros curriculares nacionais: Língua portuguesa (1998), a leitura é um processo no qual o leitor realiza um trabalho ativo de construção do significado do texto, a partir de seus objetivos, do seu conhecimento sobre o assunto, sobre o autor, de tudo o que sabe sobre a língua: características do gênero, do portador, do sistema de escrita.

Para contemplar todo o trabalho de desenvolvimento de leitura da revista foi proposta a interpretação individual do texto lido, na qual os alunos fizeram suas considerações finais por meio de relato escrito, dentre os quais se destacam alguns exemplos

A história em quadrinhos é muito interessante pois, além de ser atrativa retrata alguns fatos muito importantes de serem comentados, pois é a realidade. Falar sobre as pedras não é muito comum, portanto, é muito interessante quando podemos perceber a sua importância em um material que prenda nossos olhos e nos faça abri-los um pouco mais para a nossa realidade. Gostei muito do trabalho, foi uma ideia perfeita para nós jovens acordarmos um pouco mais.

Minha opinião sobre esse trabalho didático é que adorei o conteúdo e as ilustrações nas quais relatam coisas reais, pois a mineração, a extração de minerais sem nenhum conhecimento e cuidado pode levar causas negativas para o minerador e para a região.

Esta revista chama atenção do leitor tanto pelas ilustrações, quanto pela linguagem aplicada. Trabalho muito bem feito no qual merece total atenção e reconhecimento de todos aqueles que forem ler.

O conteúdo da revista mostra uma linguagem voltada para o público jovem que consegue por meio de imagens entender a mensagem proposta pelos autores. Contém personagens carismáticos e autoexplicativos. A revista passa a mensagem ao público e ajuda no processo de conscientização sobre os problemas gerados na mineração.

O conteúdo da revista mostra uma linguagem voltada para o público jovem que consegue por meio de imagens entender a mensagem proposta pelos autores. Contém personagens carismáticos e autoexplicativos. A revista passa a mensagem ao público e ajuda no processo de conscientização sobre os problemas gerados na mineração.

Vergueiro \& Ramos (2010) fazem importantes considerações ao retratar o público do Ensino Médio e ressaltam que, nesta fase de mudanças de personalidade, os alunos não aprovam qualquer tipo de material, muitas vezes questionam o que é oferecido em sala de aula. Nas produções próprias, os estudantes buscam reproduzir assuntos mais próximos do seu cotidiano (p. 28 e 29). Portanto, o que se percebe nos escritos dos alunos é o valor estabelecido por meio da leitura da realidade, realçando a importância atribuída ao considerar a identidade e a cultural local.

No relato dos alunos foi notada a repercussão do recurso das imagens na arte sequencial das HQs. Para Paiva \& Ribeiro (2017), o sucesso dos quadrinhos está no uso de imagens em situações contextuais que facilitam o entendimento da leitura.

Avaliação do produto: A análise das respostas ao questionário mostrou que a revista de HQs foi bem aceita e obteve uma conceituação 'ótimo' pela maioria dos professores avaliadores, em todos os itens avaliados. 21 professores participaram da avaliação. Tabela 1.

Foram perguntados quais aspectos da revista poderiam ser melhorados. A maior parte dos avaliadores não encontrou pontos a melhorar, apenas dois ressaltaram que em alguns momentos as imagens se mostraram 'agressivas'.

Tabela 1. Questões relativas ao produto educacional (respostas em percentagens)

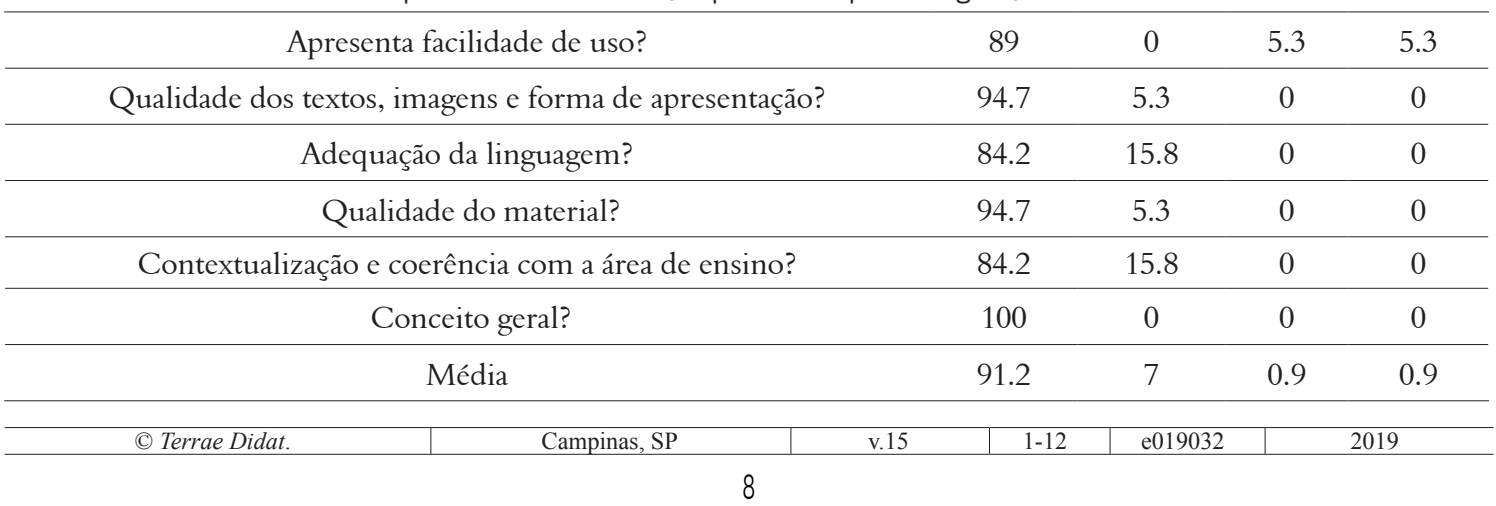


Tabela 2. Levantamento dos pontos positivos do produto educacional

\begin{tabular}{cc}
\hline Informações levantadas pelos professores & $(\%)$ de indicações \\
\hline Clareza da linguagem e objetividade ao lidar com o tema. & 36.8 \\
\hline Estimula a capacidade do senso crítico. & 31.6 \\
\hline Qualidade do material: papel, colorido e imagens. & 21.1 \\
\hline Aborda um problema local por meio da ludicidade. & 10.5 \\
\hline
\end{tabular}

Foi perguntado quais os pontos positivos da EQ apresentada. As respostas estão apresentadas na Tabela 2.

Os comentários indicam que a HQ pode prender a atenção dos estudantes. Menegazzi (2014) afirma que as HQs despertam o interesse da maioria dos jovens, devido à ascendência de imagens, por retratarem situações próximas ao cotidiano do aluno, sobretudo ressalta que não há perda da profundidade e objetividade dos assuntos tratados.

Nesse sentido, os recursos visuais, tal como os desenhos e seus esboços detalhados e coloridos, foram lembrados como um aporte importante para retratar as experiências vividas principalmente por alguns alunos e professores, que vivem próximos às áreas de mineração de rochas ornamentais.

Para Santos (2006), a imagem carrega consigo as potencialidades cognitivas da visualidade. $\mathrm{Na}$ produção artística revela a ideia e o pensamento. Segundo a autora, a imagem é a representação simbólica da realidade, do mundo interior e exterior. Além de tudo, a imagem tem papel de agregar significados, formas, comportamento real do dia-a-dia, mostrando e exteriorizando o que é subjetivo, concretizando por meio do objeto a criatividade.

A informação transmitida por meio da 'ludicidade' foi outro importante recurso que chamou a atenção dos avaliadores, o que para Anjos (2014), é uma ocorrência de todos os tempos, é parte integrante da vida de todo ser humano. Ela é tudo quanto diverte e entretém o ser humano e envolve uma ativa participação. Processa-se tanto em torno do grupo como, das necessidades individuais.

Perfazendo uma série de recursos utilizados pela HQ os avaliadores também destacaram o desenvolvimento da capacidade crítica e a objetividade do tema como importantes recursos auxiliadores do ensino, os quais viabilizam diferentes contextos e produzem informações vinculadas aos temas sociais, éticos, de saúde e meio ambiente. Portanto, torna-se um material rico para trabalhar os conteúdos transversais, pois tem boa aceita- ção entre alunos e contribui para que os alunos se apropriem dos conteúdos de maneira crítica e construtiva (Brasil, 1997, p. 33).

Em seguida, são transcritas algumas considerações que demonstram o valor dado pelos professores que, com muito profissionalismo e dedicação contribuíram para o desenvolvimento dessa ferramenta didática, a qual tem por objetivo efetivar a construção e promoção do conhecimento do leitor acerca das consequências advindas da extração de rochas ornamentais.

'Criar e utilizar a história em quadrinhos é uma iniciativa superpositiva que agregará muito sobre a construção do aprendizado acerca do tema proposto. Além de envolver o lúdico no processo, é o popular "aprender brincando". Desse modo, a HQ consolidará o entendimento dos discentes, uma vez que nela estão registradas as descobertas que os alunos fizeram na pesquisa de campo, sob a sua orientação.'

'Levando em conta o contexto, isto é, a escola localizada próxima ao Rio Pomba, que tem suas águas ameaçadas pelo esgoto e pelas indústrias que nele lançam detritos, a história desenvolvida pelos quadrinhos convida a reflexão sobre a necessidade de preservação do Rio Pomba.

'Gostei muito do material. Ele é muito criativo. Creio que seja sim de muita valia trabalhar com os alunos usando esse material. Principalmente por se tratar de um material que é bem a "cara" dos jovens. Foge bem daquele cenário apresentado nos livros.

'Toda forma de conscientização de proteção ao meio ambiente é válida, principalmente quando se chama a atenção para a problemática de forma divertida, sendo um diferencial para a assimilação e tentativa de resolução do mesmo.

'Acredito que toda ação em prol de uma educação de qualidade é válida sempre. Embora a história seja fictícia, ela busca uma reflexão

\begin{tabular}{c|c|c|c|c|c}
\hline (C) Terrae Didat. & Campinas, SP & v.15 & $1-12$ & e019032 & 2019 \\
\hline
\end{tabular}


sobre as mudanças e desequilíbrios causados pelo homem no ambiente em que vive (no caso as pedreiras). O processo ensino-aprendizagem terá sempre um resultado positivo quando associado a diferentes métodos; por isso a história em quadrinhos fecha com sucesso esse ciclo de aprendizagem que você promoveu aos estudantes da nossa escola. Aliás, todas as ações promovidas desde o seu primeiro contato com alunos e professores foram muito importantes para a conscientização do nosso espaço em comum, nosso meio ambiente.

\section{Conclusões}

A estratégia da construção de Histórias em Quadrinhos, envolvendo o que se ensina, estabelece uma forte ligação cognitiva de atores que se envolvem nas narrativas. Este trabalho refere-se à história de dois super-heróis, que supostamente encontram no desenvolvimento sustentável a estratégia para enfrentar o desafio de mudar comportamentos e atitudes para salvar uma cidade do desgaste natural, causado por uma mineração.

O trabalho ultrapassa a simples aprendizagem que capacita para leituras do mundo. Cria e motiva os atores protagonistas de forma dinâmica e divertida, com dialogicidade acerca de fundamentos éticos, ideias de justiça e redução das desigualdades. A trama básica é familiar e sedutora, a linguagem é dinâmica (ativa) com questões lógicas e o foco principal na sustentabilidade, que envolve princípios e conceitos que incorporam valores da natureza e busca fortalecer a ética, que estimula a sensibilidade ecológica e os valores emancipatórios dos leitores.

A linguagem visual influencia os sentimentos humanos por meio de símbolos e imagens. Esta estratégia apresenta efeitos semelhantes ao uso de jogos. A incorporação da História em Quadrinhos - HQ - pode possibilitar a ampliação dos esquemas sensório-motores ou conceituais já existentes nos atores envolvidos (Quadrinistas).

A teoria da equilibração de Piaget estabelece que o equilíbrio entre a assimilação e a acomodação é considerado como mecanismo auto regulador para interação eficiente com o meio. Na perspectiva Vigotskyana, o ser humano desenvolve aprendizagem de forma plena quando existem várias possibilidades disponíveis.

Os recursos, aliados às dimensões de conteúdo, fortificam e ampliam a aprendizagem. Há o desen- volvimento dos conteúdos no âmbito conceitual, atitudinal e procedimental, contribuindo para o direcionamento de uma aprendizagem efetiva para o saber fazer e desenvolver habilidades para a resolução de situação problemas. A HQ pode ser usada como objeto de aprendizagem que associa conteúdos, imagens e símbolos, contribuindo para o entrosamento de atores (equipe). Desenvolve a atenção, o interesse, a satisfação em participar e na autonomia intelectual. Tem clima tensão, ritmo e evoluções.

\section{Agradecimentos}

Agradecemos, pelo apoio ao trabalho, à Universidade Iguaçu, Campus Itaperuna e ao Colégio Paiva.

\section{Referências}

Albuquerque, M. P. (2010). A leitura e a atuação do professor das séries iniciais. Trabalho de Conclusão do Curso de Letras, Universidade Federal do Rio Grande do Sul, Porto Alegre, Brasil. Retirado de https://www.lume.ufrgs.br/bitstream/handle/10183/29348/000775782.pdf?sequence $=1 \&$ isAllowed $=y$.

Anjos, J. A. (2014). A importância das atividades lúdicas nas aulas de Educação Física no processo ensino aprendizagem. (Trabalho de Conclusão do Curso de Licenciatura em Educação Física, Universidade de Brasilia, Brasilia, Brasil). Retirado de http://bdm.unb.br/bitstream/10483/6970/1/2013 JairoAlvesdosAnjos. pdf. Acesso 12.03.2019.]

Assis, L. M.; \& Marinho, E. S. (2016). História em quadrinhos: um gênero para sala de aula, In: Nascimento, L.; Assis, L. M.; Oliveira, A. M. (Orgs.). São Paulo: Blücher. Linguagem e Ensino do Texto: Teoria e Prática. São Paulo: Blücher. p. $115-126$.

Bugay, N. (2004). Os Gatunos. Santa Catarina: Florianópolis. Editora UFSC.

Campbell, J. O. (2007). Herói de mil faces. São Paulo: Pensamento.

Campos, J. V.; Wolf, P. H.; \& Vieira, M. L. H. (2014) Desenvolvimento de Personagens: a psicologia arquetípica como ferramenta de criação e concepção de personagens para uma série animada. Projetica, 5(1), 09-24.

Caruso, F.; \& Silveira, C. (2009). Quadrinhos para a cidadania. História, Ciências, Saúde - Manguinhos, 16(1), 217-236.

Dalacosta, K.; Kamariotaki P. M.; Palyvos, J.A.; \& Spyrellis, N. (2009). Multimedia application 
with animated cartoons for teaching science in elementary education. Computers \& Education, 52(s/n), 741-748.

Eisner, W. (1999) Quadrinhos e arte sequencial. São Paulo: Martins Fontes.

Ferreira, R. V. J.; Godoy, A. R. G. L.; Mendes, P. A. P.; \& Tocantins, A. C. T. (2016). Processos de compreensão da história em quadrinhos em um protocolo de leitura: uma análise transversal de estratégias de leitura. Educação em Debate. 71(jan/ jul.), 195-208.

Giesta, N.C. (2002). Histórias em Quadrinhos: Recursos da Educação Ambiental. In: Ruscheinsky, A. (org.) (2002). Educação Ambiental: Abordagens Múltiplas. Porto Alegre: Artmed.

Gomes, M. B. (2018). Once upon a time: protagonismo coletivo transdimensional. Temática. XIV(11). novembro/2018. Retirado de http:/www.periodicos.ufpb.br/ojs2/index.php/tematica/article/ view/42896/21391

Guimarães, E. (1999). Uma caracterização ampla para a história em quadrinhos e seus limites com outras formas de expressão. Anais do XXII Congresso Brasileiro De Ciências Da Comunicação. Rio de Janeiro, RJ.

Iannone, L.R. E R.A. (1994). O mundo das histórias em quadrinhos. São Paulo: Moderna.

IBGE. Instituto Brasileiro de Geografia e Estatística. Retirado de https://cidades.ibge.gov.br/brasil/rj/ santo-antonio-de-padua/panorama.

Junqueira, H.; \& Del Pino, J. C. O. (2007). A temática ambiental e seu potencial educativo nas histórias em quadrinhos de Mauricio de Souza. Retirado de : http://www.fep.if.usp.br/ profis/arquivos/ vienpec/CR2/p225.pdf.

Krüger, C. H.; \& Michels, J. A. (2018). Colaboração do gênero textual história em quadrinhos no desenvolvimento da leitura e escrita. Rev. Bras. Psico. e Educ., 20(1), 20-31.

Lei de Diretrizes e Bases da Educação Nacional. (12 de dezembro de 2006). Retirado de http://www2.senado.leg.br/bdsf/bitstream/handle/id/70320/65.pdf.

Luyten, S. M, B. (2011). Quadrinhos em sala de aula: um recurso de aprendizagem. Salto para o futuro. TV Escola. Retirado de: http://tvescola.mec. gov.br/tve/salto-acervo/interview:jsessionid=EFCD103D96DF85218A11DOF7B69C430?idInterview $=8459$.

MaffesolI, M. 1995 A Contemplação do Mundo. Porto Alegre: Artes e Ofícios,

Marinho, A. M. S. (2004) A educação ambiental e o desafio da interdisciplinaridade. (Dissertação de Mestrado em Educação, Pontifícia Universidade Católica de Minas Gerais, Belo Horizonte, Brasil). Retirado de http://www.biblioteca.pucminas.br/ teses/Educacao_MarinhoAM_1.pdf

Massarini, S. (2019). A criação de personagens. Retirado de : http://www.massarani.com.br/rot-criar-per- sonagens-roteiro-cinema.html.

Moretto, J.; Nakata, M. K. (2018. Dibujo expresional y creatividad: el pensamiento visual en beneficio del proyecto. Procesos. 5(s/n) 106-112.

Paiva, F. S.; Ribeiro, E. N. (2017 As imagens dos quadrinhos: aplicações e dificuldades no uso educacional. Revista Intresaberes. 25 (12) 46-59.

Parâmetros curriculares nacionais: apresentação dos temas transversais, ética. (1997). Retirado de http://portal. mec.gov.br/seb/arquivos/pdf/livro082.pdf .

Parâmetros curriculares nacionais: Língua portuguesa. (1997) Retirado de http://portal.mec.gov.br/seb/ arquivos/pdf/portugues.pdf .

Peiter, C. C.; Carrisso, R. C. C.; \& Pires, D. C. B. (2011) O Arranjo Produtivo Local de Santo Antônio de Pádua. Retirado de : http://mineralis.cetem. gov.br/bitstream/cetem/1181/1/O\%20Arranjo\%20Produtivo\%20Local\%20de\%20Santo $\% 20$ Ant $\%$ C3\%B4nio.pdf.

Pereira, M. L. D. A.; \& Oliveira, P. E. D. F. (2016). Física em Ação através de Tirinhas e Histórias em Quadrinhos. Caderno Brasileiro de Ensino de Física, 33(3) 896-926.

Prado, C. C.; Sousa Junior, C. E.; Pires, M. L. (2017 Histórias em quadrinhos: uma ferramenta para a educação e promoção, RECIIS - Rev Eletron Comun Inf Inov Saúde. 2(11) 1-12.

Programa Nacional Biblioteca na Escola (PNBE).(2008) Retirado de http://portal.mec.gov.br/expansao-da-rede-federal/195-secretarias-112877938/seb-educacao-basica-2007048997/12516-pnbe.

Públio Júnior, C. (2018. O docente e o uso das tecnologias no processo de ensinar e aprender. RIAEE - Revista Ibero-Americana de Estudos em Educação. 13(03) 1094-1108.

Rauber, S. C.; \& Medina, R. D. (2019). Trabalhando histórias em quadrinhos como um recurso didático para as aulas de ciências. Retirado de : https://repositorio.ufsm.br/bitstream/handle/1/759/Rauber_Simone_da_Costa.pdf? sequence $=1$ \&isAllowe$\mathrm{d}=\mathrm{y}$.

Santo, E. R. E.; \& Santos, R. R. (2012) Contribuições das histórias em quadrinhos de Chico Bento para a educação ambiental. Rev. eletrônica Mestr. Educ. Ambient. 28(jan a jun) 479-493.

Santos, L. (2006). A leitura de imagens visuais como recurso pedagógico no ensino da arte: uma experiência com alunos do ensino fundamental. Monografia do Curso de Especialização em Artes, Universidade Federal de Pelotas, Pelotas, RS. Retirado de https://wp.ufpel. edu.br/especializacaoemartesvisuais/files/2013/06/ Simone-Vaghetti-Ribeiro-2013.pdf.

SENAC Serviço Nacional de Aprendizagem Comercial, SENAC. (2014). A importância dos diálogos para a narrativa cinematográfica. Revista de Cinema. Retirado de http://revistadecinema.com. br/2014/08/a-importancia-dos-dialogos-para-a- 
-narrativa-cinematografica/

Tanino, S. (2011) Histórias em quadrinhos como recurso metodológico para os processos de ensinar. Trabalho de Conclusão do Curso de Pedagogia. Londrina, PR: Universidade Estadual de Londrina..

Testoni, L. A.; \& Abib, M. L. V. S. (2003). A utilização de histórias em quadrinhos no ensino de física. In. Anais do IV ENPEC, São Paulo Bauru.
Vergueiro, W.; \& Ramos, P. (Orgs). (2009) Os quadrinhos (oficialmente) na escola: dos PCN ao PNBE. In: Vergueiro, W.; R., P. (Orgs) Quadrinhos na educação. São Paulo: Contexto.

Weschenfelder, G. V.; \& Kronbauer, L. G. (2010). As HQs e a formação da consciência moral das crianças. Anais do Congresso Nacional de Filosofia e Educação, Caxias do Sul, RS, Brasil.+ 